\title{
O PROFESSOR E A CONSTRUÇÃO DO CONHECIMENTO
}

\author{
Dinara Pereira Lemos Paulino da Costa dinarapereira@uol.com.br ${ }^{1}$
}

\section{Resumo}

O presente trabalho discute a importância do papel do professor em promover na escola um ambiente intencionalmente organizado, com vistas a favorecer a construção do conhecimento pelo aluno. Nesta perspectiva o professor deve conhecer o desenvolvimento e como se dá a construção do conhecimento, os processos envolvidos e seu papel selecionando conteúdos que os alunos queiram aprender, que faça sentido para os mesmos, que os instigue a busca e a pesquisa.

Palavras chave: Conhecimento, professor, aluno

\begin{abstract}
The present work argues the importance of the paper of the teacher in promoting in the school an environment intentionally organized, with sights to favor the construction of the knowledge for the student. In this perspective the professor must know the involved development and as if of a construction of the knowledge, processes and paper selecting contents that the student want to learn, that he makes sensible for the same ones, that them he instigates the search and the research.
\end{abstract}

Key words: knowledge, teacher, student

\section{Introdução}

O ser humano desde o seu nascimento busca conhecer e se adaptar ao "mundo". Segundo Gonzáles Pecotche, “o saber é a razão de ser da existência do homem na terra, a

\footnotetext{
${ }^{1}$ Mestre em Educação pela Universidade Estadual de Campinas UNICAMP. Professora substituta do Curso de Pedagogia da Universidade Federal de Goiás - Campus de Jataí.
} 
primeira e a última de suas tarefas". Não há começo absoluto. Estaremos caminhando pela vida, agindo, interagindo, modificando e nos transformando em nossa caminhada.

Mas, como se dá esse processo?

Que caminhos ou mecanismos envolvem esta construção?

Segundo Piaget o sujeito conhece o mundo que o rodeia a partir da sua interação (sujeito-objeto do conhecimento). Neste processo sujeito e objeto são faces de uma mesma moeda ou dois pólos dentro de uma mesma totalidade.

Para Franco (1994, pag 32)

Interação não é, portanto, um processo de "toma lá-dá-cá". Só pode ser entendida como um processo de simultaneidade e, portanto de movimento entre dois pólos que necessariamente se negam, mas que, conseqüentemente, se superam gerando uma nova realidade.

Nessa perspectiva o ser humano renasce a cada descoberta, cria e se refaz em suas ações e pensamentos. "Não se pode tomar banho duas vezes no mesmo rio..." Neste ritual dialético, o homem se constrói desde o seu nascimento até o fim de seus dias.

Mas, como os professores compreendem este processo? Como acreditam que se da á construção do conhecimento dele mesmo e do seu aluno?

Esta pergunta deveria ser a primeira preocupação dos cursos de formação inicial e continuada, pois dependendo da resposta, ou seja, da concepção do professor de como se da este processo, será a sua postura frente aos alunos e frente ao objeto do conhecimento (conteúdo).

\section{Desenvolvimento}

A construção do conhecimento se dá pelo processo de equilibração, que permite ao sujeito mudar de estados de equilíbrio aproximados para outros, qualitativamente diferentes, passando por muitos desequilíbrios e reequilibrações.

Existem dois processos fundamentais, que são componentes de qualquer equilíbrio cognitivo, a assimilação que refere-se a incorporação de um elemento exterior (objeto, 
idéia, acontecimento, etc), num esquema motor ou mental do sujeito e a acomodação, sendo esta, a necessidade em que a assimilação se encontra de considerar as particularidades próprias dos objetos a serem assimilados.

Todo esquema assimilador tenta incorporar a si próprio os elementos externos que são compatíveis com a sua natureza. Nesse processo, a atividade do sujeito torna-se essencial. A criança assimila quando, pega, joga, bate, abre, fecha, aperta, evoca, representa, explora o que a interessou. Simultaneamente esse sujeito se reorganiza para assimilar o objeto do seu conhecimento. Nessa "dança” para conhecer sujeito e objeto se modificam, se completam, o sujeito enquanto investigador e criador de novos esquemas, e o objeto oferecendo a este suas características, ao mesmo tempo em que vai sendo enriquecido pelo que o explora, com suas ações físicas e mentais. Nessa troca o sujeito se constrói desde o seu nascimento.

O bebê traz consigo os reflexos para a sua adaptação ao mundo, sugar, pegar, ouvir, dentre outros, que os exercitando serão transformados em um saber fazer, ou esquemas de ação ou subsistemas. Estes são consolidados através do exercício e vão se combinando, permitindo assim, a aquele pequenino ser, a possibilidade de buscar o que existe para conhecer.

Na construção do conhecimento, o objeto não é somente uma "coisa", mas algo que incita a ação, que mobiliza o sujeito, que o desequilibra. O objeto é a mediação entre o sujeito que se constrói a partir dessa interação, neste sentido ele é a negação do sujeito e o sujeito construído a negação da negação.

A forma como os professores compreendem este processo faz toda diferença na sua prática docente, pois compreendendo o seu papel de criador de atividades, mobilizador e incentivador das ações dos alunos, ele de fato poderá posssibilitar a construção do conhecimento, ou não. Favorecer que os alunos gostem, que queiram, que se envolvam com os conteúdos a serem propostos é o melhor caminho, pois a mente e toda sua energia estarão voltados a resolução do seu "problema". Possibilitar desequilíbrios, movimentar as mentes, eis o nosso maior desafio enquanto professores! 
Os desequilíbrios são fontes de progresso no desenvolvimento dos conhecimentos, pois só os desequilíbrios obrigam um sujeito ultrapassar o seu estado atual e procurar seja o que for em direções novas.

Piaget 1977, pag23.

Os desequilíbrios são meios para o desenvolvimento. Estes comportam um fator motivacional, que impulsiona a ação na busca de reequilibrações específicas. O desequilíbrio não se encontra nos "objetos" e sim na falta de ajustamentos entre sujeito e objeto. É na assimetria entre afirmações e negações que surgem as perturbações, ou seja, os problemas que o aluno quer solucionar, as respostas que busca para compreender algo ou se apropriar de um novo conhecimento.

Vemos, portanto a importância do meio para a construção do conhecimento. Quanto mais este for rico e diversificado, criando situações e experiências que desequilibrem mais a criança ou o adulto aprende e ou desenvolve.

Mencionamos aqui a criança, por estar em pleno processo de construção das estruturas da inteligência. Essas estruturas são orgânicas e não programadas, e existem na criança ao nascer como possibilidades de vir a ser. Essas estruturas que formam o sistema cognitivo são um conjunto de elementos que permitem ao ser, estabelecer trocas com o meio, e uma vez construída se fecha e se conserva numa totalidade que, ao mesmo tempo abertas, possibilitam novas regulações que podem resultar em transformações de esquemas, representações e conceitos.

Nos adultos o processo de equilibração acontece da mesma forma, constituindo-se em perturbações que resultam em compensações através das regulações ou lacunas, sendo preciso várias reequilibrações, para alcançar um estado de compreensão melhor.

Por exemplo, nos desequilibramos durante uma aula sobre as abstrações. Estudamos, refletimos, questionamos, trocamos idéias com os colegas, perguntamos aqui e ali, voltamos para a casa, estudamos novamente, recordamos de outros conteúdos e assim através das regulações, compensamos ou não; ou seja, adquirimos um novo conceito, modificamos um conceito anterior ou permanecemos com os mesmos esquemas, porém 
ativados, precisando ainda de novas reflexões até a tomada de consciência, ou seja, a construção de um novo esquema mental. A negação existe quando não compreendo o que estudo, sendo um conteúdo novo, me desequilibro (perturbação) e preciso de regulações, que me permitam alcançar possíveis compensações.

...o equilíbrio não é de modo nenhum um ponto de paragem, porque uma estrutura concluída pode sempre dar origem a exigências de diferenciações em novas subestruturas ou a integrações em estruturas mais amplas. A razão desta melhoria necessária de qualquer equilíbrio cognitivo é então que o processo de equilibração como tal provoca de maneira intrínseca uma necessidade de construção e, portanto, de ultrapassagem, em virtude do próprio fato de só assegurar uma certa conservação estabilizadora no interior de transformações das quais esta conservação constitui apenas a resultante: por outras palavras, compensação e construção são sempre indissociáveis."

Piaget 1977, pág 46.

Para se desequilibrar são necessárias ocorrerem às perturbações que podem ser de oposição às acomodações ocasionadas pela resistência do objeto do conhecimento, ou por lacunas que deixam necessidades insatisfeitas. Nem toda lacuna corresponde a uma perturbação. Para ser perturbação, o objeto deve significar algo para o sujeito, ser assimilável, senão o mesmo o despreza, não havendo modificações ou construção de novos esquemas, ou integração das estruturas. Somente existem lacunas quando se trata de um elemento que o sujeito precisa para resolver um problema que o incita. Neste sentido a escola se faz necessária e o professor torna-se um grande parceiro como favorecedor ou criador de desequilíbrios. Estarão os professores oferecendo atividades que causem perturbações? Os conteúdos são significativos, envolventes e desafiadores?

Ora, muitas vezes observamos atividades pobres e repetitivas, resumindo-se em papéis brancos e giz de cera. Não que não sejam importantes, mas, para a construção das estruturas é preciso muito mais. Sabemos que essas atividades não despertam no sujeito as contradições, não havendo, portanto modificações nas estruturas, pois o progresso do conhecimento consiste justamente nessa busca incessante de eliminação das contradições. 
Conhecer é abstrair informações (objeto/conteúdo) e transformá-las em conhecimento. Existem duas grandes abstrações que fazem parte do processo de equilibração, abstrações estas presentes em todos os estágios do desenvolvimento humano. A abstração empírica tira suas informações dos objetos como tais, ou das ações do sujeito sobre as propriedades observáveis do objeto, cor, sabor, odor etc. A abstração reflexionante apóia-se sobre as coordenações das ações do sujeito, se dividindo em pseudo-empirica, que necessita do objeto presente para realizar suas coordenações, e a abstração refletida, sendo esta o resultado de uma abstração reflexionante, assim que se torna consciente.

As abstrações empíricas e pseudo-empíricas estão presentes nos níveis mais elementares de pensamento, mas existem em todos os níveis até no homem da ciência.

Sem excluir de nenhum modo sua coexistência possível, a evolução das abstrações pseudo-empiricas e refletidas é, pois, caracterizada por essa inversão de suas proporções, as primeiras, perdendo seu valor relativo (sem jamais desaparecer, mesmo no homem da ciência), as segundas contrariamente aumentando.

Piaget (1995, pag 277)

A abstração reflexionante traz sempre maiores possibilidades de construção das formas em relação aos conteúdos, formas essas que permitirão o sujeito operar no mundo e estabelecer relações cada vez mais elaboradas e complexas.

Assim, podemos compreender a dificuldade da escola. Essa quer ensinar o que precisa ser construído. Ela parte da premissa de que as crianças já possuem a "forma" e trabalham com conteúdos formalizados, que as crianças não conseguem compreender. Não estão preocupados por desconhecerem o processo de construção do conhecimento, com a construção das estruturas, pois apesar de inúmeras pesquisas, muitos educadores pouco sabem a respeito do desenvolvimento infantil, e quando estão na escola acreditam estar fazendo o melhor e de fato ensinando o que precisa ser construído.

\section{Considerações Finais}

Faz-se necessário que os professores se tornem de fato pesquisadores e que sejam apaixonados pela construção do seu próprio conhecimento. Que estudem, busquem, 
ressignifiquem suas experiências para que os alunos encontrem nas escolas o encantamento, a magia que deve permear a descoberta, e a reinvenção do conhecimento. Ensinar o gosto pelo saber deve ser nossa primeira meta enquanto educadores! Aprender é bom demais! E aprender o que? Tudo o que for possível para o nosso bem e o bem da sociedade.

Que a escola exerça seu papel de desencadeadora de conflitos cognitivos, sociais e morais e que permita que os alunos construam suas estruturas do conhecimento, sua forma de pensar, e que sejam livres para expressar, errar, reorganizar e acertar!

\section{Referências Bibliográficas}

PECOTCHE, Carlos Bernardo G. Introdução ao Conhecimento Logosófico. Editora Logosófica, 2000.

PIAGET, Jean. O Desenvolvimento do Pensamento: Equilibração das Estruturas Cognitivas. Lisboa: Publicações Dom Quixote, 1977.

PIAGET, Jean. Abstração reflexionante. Porto Alegre: Artes Médicas, 1995.

MACEDO, Lino. Ensaios Construtivistas. São Paulo: Casa do Psicólogo, 1994.

BECKER, Fernando, FRANCO, Sergio R. K. Revisitando Piaget. Porto Alegre: Editora Mediação, 2002. 